\title{
The Plague of Plagiarism: Prevention and Cure!!!
}

\author{
Suvarna Satish Khadilkar ${ }^{1}$
}

Received: 3 October 2018/Accepted: 3 October 2018/Published online: 12 October 2018

(C) Federation of Obstetric \& Gynecological Societies of India 2018

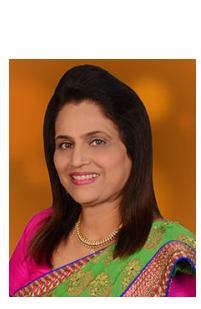

\begin{abstract}
About the Author
Dr. Mrs. Suvarna Satish Khadilkar is the editor in chief of this journal. She is currently working as Consultant GyneEndocrinologist, Bombay Hospital Institute of Medical Sciences and Medical Research Centre, Mumbai. In the past, she worked as an Associate Professor and Unit Chief at JJ Group of Hospitals and Grant Medical College [GMC], Mumbai, and thereafter in the capacity of the Professor and Head in Department of Obstetrics and Gynecology, Government Medical College, Kolhapur, Maharashtra. She has been an undergraduate and postgraduate teacher and examiner, Mumbai University and Maharashtra University of Health Sciences. Pursuing her interest in endocrinology, she acquired Diploma in Endocrinology from the prestigious University of South Wales, UK, and has been appointed as a recognized teacher in endocrinology in University of South Wales. She is the Treasurer of FOGSI. She has held many prestigious positions like President of Indian Menopause Society, Chairperson of Reproductive Endocrinology Committee of FOGSI, President of Association of Medical Women in India, Mumbai. She is currently the librarian of Mumbai Ob-Gyn Society. She has published six textbooks and more than 70 articles at national and international levels. She is recipient of 30 awards for her research work including the Young Scientist Award.
\end{abstract}

\begin{abstract}
Plagiarism is a serious form of scientific misconduct. Literal meaning of the Latin word "to Plagiare"

Prof. Suvarna Satish Khadilkar MD DGO FICOG, CIMP, Diploma in Endocrinology (UK) is Editor in Chief of Journal of Obstetrics and Gynecology of India, and Treasurer, FOGSI; she is Consultant GyneEndocrinologist, Bombay Hospital and Medical Research Centre, Mumbai, Former Professor and Head, Dept of Ob-Gyn, RCSM, Government Medical College, Maharashtra and Associate Professor and Unit Chief Grant Medical College and Cama and Albless Hospital, Mumbai.
\end{abstract}

Suvarna Satish Khadilkar suvarnakhadilkar@yahoo.com; suvarnakhadilkar2@gmail.com

1 Bombay Hospital and Medical Research Centre, 12 New Marine Line, Mumbai 400020, India is "to steal or to kidnap". The act of taking the writings of another person and passing them off as one's own is plagiarism. It implies intellectual theft in the world of medical writing. The "copy and paste" culture is becoming rampant all over the world after the advent of electronic publications, and Indian medical literature is no exception. This editorial will enlighten aspiring authors and readers about various forms of plagiarism and reasons for engaging in plagiarism. More so, it will also elaborate on how to prevent and cure this plague. Possible consequences that authors may face on detection of the plagiarism are also discussed. I am concluding my editorial series on medical writing with this last editorial of the year. I sincerely hope that these editorials helped authors and readers and this 
journal continues to receive high-quality papers written with the greatest honesty and integrity.

Keywords Plagiarism - Scientific misconduct - Ethics . Scientific research

\section{Introduction}

\section{“Great Men May Think Alike! But They Don't Write Alike"}

Plagiarism is one of the most serious forms of misconduct as it implicates intellectual theft. After the electronic media has completely taken over journal publications, the literature is more easily available, accessible and most importantly, easily reproducible. The world of medical writing is infested with this bug plagiarism! This plague of plagiarism is spreading fast, and we need to look at preventing its spread and curing it before the scientific community becomes victim of this epidemic.

Before entering into the complex phenomenon of plagiarism, please understand the various principles of integrity. Three commonly used terms, Ethics, Guidelines and Law, are often confused and many a times used interchangeably. For clarity on this, readers may refer to our editorial published in previous issue of this series on medical writing [1].

This editorial will focus on various forms of plagiarism, discuss actions taken if plagiarism is detected and will address how to avoid it.

\section{What is Plagiarism? [2, 3]}

The various terminologies used in this context have been summarized well by Kumar et al. The term is derived from "plagiare" (Latin word for "to steal/kidnap"). "Plagiarius" usually refers to a kidnapper. The Oxford dictionary defines plagiarism as "the action or practice of taking someone else's work, idea, etc., and passing it off as one's own; literary theft". The Encyclopedia Britannica defines plagiarism as "the act of taking the writings of another person and passing them off as one's own".

In the medical scientific community, World Association of Medical Editors (WAME) and Committee of Publication Ethics (COPE) have provided similar definitions.

WAME defines plagiarism as "the use of others' published and unpublished ideas or words (or other intellectual property) without attribution or permission and presenting them as new and original rather than derived from an existing source".
The matter of scientific plagiarism has been dealt with extensively by COPE. The definition given by COPE is "Plagiarism ranges from the unreferenced use of others' published and unpublished ideas including research grant applications to submission under new authorship of a complex paper, sometimes in a different language. It may occur at any stage of planning, research, writing or publication; it applies to print and electronic versions".

\section{What can be Plagiarized?}

In reality, anything can be plagiarized. It may be ideas, concepts, hypothesis, title, text, materials and methods, entire clinical data set, discussions, charts, tables, figures and videos, etc.

\section{Various Forms of Text and Image Plagiarism: $[4,5]$}

- Verbatim/mosaic: Using the same words/phrases/sentences, exactly as it has appeared elsewhere without using a quotation.

- Paraphrasing: Using vast content from elsewhere by just changing the language.

- Cyber plagiarism: Copying content from the Internet.

- Image plagiarism: Using image(s) published elsewhere as their own original. It is not enough if original source is cited in the references, the source must be cited immediately below the image and must write reproduced with permission after obtaining due permission.

\section{What is Self-Plagiarism?}

While the above have dealt with using others' work as original, a unique form of plagiarism is "Self-plagiarism" $[6,7]$.

These include

- Duplication

- Augmentation

- Segmentation

- Text recycling

Duplication refers to the use of the same content with different titles and/or in different journals. It is sometimes referred to as misconduct. Duplicate publication can also refer to the practice of publishing the same information a second time without acknowledging the first publication. 


\section{Why Does Duplication Matter?}

In simple terms, one patient's details should be counted only once. It is like a census. Hence, duplication is dishonesty and breaches copyright rules. Not only does it waste time and resources of honest publication efforts, preventing other authentic papers from appearing, but it can also distort findings of systematic reviews and metaanalyses. Eventually, it can distort research records, and result is erroneous conclusions and endanger public health. Some glaring instances have been reported in Indian medical literature [8].

\section{Segmentation: "Salami Slicing” [9]}

Salami publication (sometimes called bologna or trivial publication or academic polygamy) is "the practice of dividing one significant piece of research into a number of small experiments (least publishable units)". This method is used by researchers to simply increase the number of publications. It falsely increases the number of studies that appear to support it, whereas in reality there is only one study. The act of slicing one understandable and appreciable set into multiple uninterpretable chunks only wastes valuable time and resources. As an exception, the same set of data may be used in different places, in different proportions, if there is a difference in message to different readership. However, if the degree of overlap is large, it is unacceptable. To summarize, "One study one article" is correct. "One study multiple articles" is to be condemned.

Augmentation: Authors' own study published previously is expanded with more data and published second time. It is to be noted that data, once published, should not be republished. It may merely be referenced.

Text recycling: Repeating whole or a part of the article published again without following due procedure.

\section{What is Irresponsible Authorship?}

"Irresponsible Authorship" can be of various types [10-13]. Ghost authorship, guest authorship, omitting authorships, changing order of authorship which does not comply with prior mutual agreement between authors, not giving due credit to the degree of contribution of author/s amount to authorship plagiarism. The details of various types of authorship plagiarism are described in our previous editorial [1].

- Self-citations are nothing but strategic placement of self-citations to inflate bibliometric indicators. Though not entirely wrong, it is sometimes frowned upon.
- "Genie Article" An interesting form of scientific misconduct is colloquially called the "Genie Article" phenomenon or also sometimes the "Banyan Tree" approach. Just like a genie can magically bring something from thin air to reality, and just like there are stories about great minds achieving salvation and ethereal knowledge sitting under a banyan tree, there have been instances of facts, figures, numbers and statistics made to appear from nothing. A scientific paper about patients, who never existed, is a grave form of misconduct, and it is worse than plagiarism of any sort.

The tenets of ethical authorship and practices are bound to gradually change, and there is a need for constant improvement.

\section{Some Other Forms of Plagiarism}

Citation plagiarism "Citation amnesia", "the disregard syndrome" and "bibliographic negligence" are synonyms. It can be defined as wilful or negligent failure to appropriately credit other prior discoverers, so as to give an improper impression of priority. In other words, it is writing an article, disregarding some other important prior information available easily and widely in medical literature [14].

Misappropriation of data: It is literally stealing the work and results of others and publishing as authors' own.

Suppression: It is nothing but the refusal to publish important yet significant findings since the results are contrary to the interests of the potential author or his/her sponsor(s).

\section{Grading Severity of Plagiarism}

Extent, originality, position/context/type of material, referencing attribution and intention are the five different attributes considered by COPE, while grading severity of plagiarism.

With respect to "Extent" of plagiarism, the possibilities are that varying amounts of content may be taken from the article which is being plagiarized from. In worsening grades of severity, the amount may be,

- A few words

- A few sentences

- Whole paragraph

- Several paragraphs

- Whole paper 
Conceptual stealing, with respect to the "originality", in increasing order of severity is as follows: The idea which is plagiarized may be

- A widely used phrase/idea, mentioned by many authors in multiple instances in medical literature: this would constitute a lesser level of severity.

- A phrase/idea used by a small number of authors

- An original phrase/idea, which has been used by only a single author, and is unique in medical literature: this would constitute the highest level of severity.

While referencing the source also, authors have to follow some rules. If they are flaunted, it results in misconduct of plagiarism type. The grade of misconduct in increasing order of severity is as follows:

- Source fully and clearly referenced, but large portion of text is copied verbatim.

- Source partially or inaccurately referenced

- Unreferenced matter is the severe most form. Concepts, methods or discussion points are copied but totally ignored to cite the source.

There may be cases where there was intention to deceive, and others where there was no intention to deceive. Most importantly and controversially, the plagiarism is considered "misconduct" irrespective of whether it is intentional or unintentional. It is also considered misconduct whether the plagiarized article is published or unpublished. Mere intention of submitting plagiarized article for publishing is also considered misconduct.

Using some others' work with wrong paraphrasing or improper citation and copying out of ignorance refers to unintentional plagiarism. However, both are considered academic dishonesty [15]. However, authors proven to have done unintentional plagiarism may not face serious actions.

\section{Major and Minor Plagiarism}

Considering that varied possibilities exist, COPE, under the guidance of Elizabeth Wager, in 2011 has come up with suggestions as to what should constitute major plagiarism and minor plagiarism.

Plagiarism is considered to be "major" under the following circumstances.

- Any case involving unattributed copying of another person's data/findings, or resubmission of an entire publication under another author's name (either in the original language or in translation),
- Verbatim copying of more than 100 words of the original material without any citation to the source material,

- Unattributed use of original, published academic work, such as the scientific argument, structure or idea/ hypothesis of another group of author(s).

It can be considered as minor if there is,

- Verbatim copying of less than 100 words without quotation from an original work (immaterial of citation of the source), unless the text is universally accepted or has been standardized (e.g. it may be the description of a standard technique)

- Close copying (not quite verbatim, but changed only slightly from the original) of significant sections (e.g. $>100$ words) from another work (whether or not that work is cited)

\section{How to Avoid Plagiarism?}

Having understood the facts about plagiarism, it is necessary for every medical researcher to employ conscious efforts to ensure that this does not creep into any scientific work of theirs. Some user-friendly guidelines are presented here.

1. Concept: Develop an original hypothesis. Come up with original ideas and honest concepts, rather than replicating/ imitating what has been done prior or elsewhere.

2. Study design: Perform research which is well justified, well planned and appropriately designed. Taking informed consents from participants is the backbone of the study. Define contributions of each co-author, from the very beginning of the study.

3. Approval by Institutional Ethical committee: It is advisable to keep a copy of institutional ethics committee approval for a reasonable time frame, even after completion of the study.

4. Diligent literature search: Studying what available literature has to offer on the subject thoroughly is a must. The researcher must assimilate available knowledge, understand the needs of the study and organize thoughts appropriately.

5. Start writing the manuscript: After completion of conducting search and research, start writing in your own words, without looking into any other sources.

The adage goes

"Read the article, close the article, keep it away Close your eyes, open your eyes and then write away" If there is any issue with language skills, take help of 
senior author or a guide, or a translator or a native speaker.

6. Divide the write-up under standard section headings: The two areas where there is a large tendency and temptation to "copy and paste" are the introduction and discussion sub-headings. If another original work has to be attributed, paraphrase the original work, in your own words. DO NOT COPY-PASTE!!!

7. Recommendations if there is a need to copy paste verbatim

- For short quotes, use quotation marks in the sentence.

- For longer quotes, indent the entire passage

- For vast quotations, obtain permission from the publisher of the original work

- Attribute references to all of the above

- Describe all sources of information

- Remember to give acknowledgments

- Provide footnotes

8. Recommendation if there is a need to copy paste from a previously published article, which you have authored

Even for your own article published previously, it is prudent to obtain permission from the publisher.

9. Recommendation if you would like to use figures/ tables/illustrations

- Permission has to be sought for the usage of drawings or other illustrations which have been published prior

- For tables, charts, diagrams etc., citing the source directly is acceptable. Citing the reference somewhere in the text does not suffice.

- Permission should be sought to copy tables, figures, etc.

10. Duplication: Avoid writing several articles of the same type and submitting to different journals at the same time.

11. Run your final document through a plagiarism check software Immaterial of the level of diligence displayed, minor amounts of inadvertent unacceptable similarities may creep in. Running a plagiarism check using any available software should be included in the checklist of things to do prior to submitting any article to any journal.

12. Prevention of segmentation: Previous publications must be cited in the next similar publication. If there is a need to present a fragmented data from a complex study, enclose other papers (published or unpublished) that might be part of the paper under consideration. Never present your old paper with added data as new paper.

13. Copyright Law: Some instances can constitute copyright infringement. Hence, authors are strongly encouraged to become familiar with basic elements of copyright law.

Readers and authors can refer to detailed elaborate guidelines on how to avoid plagiarism published by office of research integrity [16].

\section{Why does Plagiarism Occur?}

Like any medical phenomenon, it is multifactorial [17, 18]. The factors related to writing of the article itself could be,

- Easy accessibility of information in electronic media "The Copy-Paste Culture"

- Lack of awareness that plagiarism tools exist and editors can detect copy pasting

- Authors may get overconfident after successful attempts of others/their own, and may think "Who checks"

- Poor language skills

- Lack of knowledge on the ethics of scholarly writing

- Lack of moral integrity

If the efforts, time and competence to perform goodquality research are lacking, why publish at all? Again, this is because of multiple factors such as:

- There is a pressure to publish to remain relevant in scientific circles.

- The enhancement of career prospects due to the presence of publications.

- Ambition to excel in the scientific community and the presence of fierce competition

- Pressure from seniors

- The oft-quoted "Publish OR perish" system [19]

These factors lead authors to take shortcuts towards completing a paper, under any circumstance. If authors follow unethical practises, for the fear of publish OR perish system, they must be warned that such unethical practises may subject them to "Publish AND Perish" outcome! This is because authors engaging into repeated acts of plagiarism of serious nature may be subjected to disciplinary action by appropriate authorities.

In this context, there are many plagiarism detection softwares available [20], and there is an ever-increasing list. For example, in the "iThenticate" software, files are compared with 37 million (and always getting updated) other already published research articles, which have been 
published under the auspices of hundreds of global scientific, technical and medical publishers including PubMed. It is important for the authors to know that editors use their own judgement regarding acceptability of articles for further view. The numerical results generated by plagiarism detection softwares are only an adjunct [21].

Authors could consider processing their own papers through these softwares before an actual journal submission. Either way, the editors are sure to do so. However, it must be categorically understood by all authors that the best way of preventing plagiarism is not by software checks or using techniques to fool the softwares, but by writing in an original style primarily.

\section{Plagiarism Detected: What Next?}

Despite all efforts to prevent plagiarism, if an article which has plagiarism actually gets published, reparative efforts need to be taken.

The journal may decide to publish errata, apology letter or a public notice of retraction of the published article. Apart from these, penalty may be levied on the authors based on the severity of the plagiarism [21, 22].

This can include

- Formal disciplinary action

- Author can be blacklisted for specific period

- Recommendation to medical council regarding suspending authors on grounds of unethical practices

- Criminal charges (suspension and prosecution of authors).

What actions can editors take when plagiarism is detected before accepting/publishing the articles?

- Articles can be simply rejected giving reasons

- Inform the original author and he may take necessary action

- Information to Ombudsman of medical writing, so that a wider variety of scientific professionals are aware about the details of authors making such submissions.

- If it is of serious nature, occasionally even criminal proceeding may be undertaken.

A group of like-minded editors put together the Committee on Publication Ethics (COPE), which is now an association of more than 6000 editors of medical journals of various specialties. They meet on a regular basis to discuss cases relating to publication issues, and publish their findings. Codes of practices of editors, agreed upon by most of the editors, are now made available. Consensus definitions on best practices in scientific publishing and on how to address breaches of the tenets of research and publications ethics are suggested. It is useful for the full range of medical researchers ranging from readers and authors, to editors, owners and publishers of journals. Readers are referred to www.publicationethics.org.uk for further information.

The adage "Prevention is better than cure" is apt in the context of plagiarism. There are definite benefits of avoiding plagiarism as an author.

- The author will earn immense respect amongst peers

- Each author's genuine work will contribute to the scientific progress in the field

- The author will prevent the scientific community from becoming victims of untruthful evidence

As obstetricians-gynaecologists, all of us are focused towards achieving the final goal of excellence in women's health. At an individual level, each researcher must pledge that he/she will not indulge in plagiarism and will show zero tolerance towards the plague of plagiarism.

To conclude, good ethical research practices as mentioned above will constitute a definite step towards scientific evolution which will help us go in improving quality of health of women and the community at large.

Let us all join hands and take a pledge to fight against plagiarism.

\section{References}

1. Khadilkar SS. Scientific misconduct: a global concern. J Obstet Gynecol India. 2018;68(5):331-5.

2. Kumar PM, Priya NS, Musalaiah S, et al. Knowing and avoiding plagiarism during scientific writing. Ann Med Health Sci Res. 2014;4(Suppl 3):S193-8.

3. Dhammi IK, Ul Haq R. What is plagiarism and how to avoid it? Indian J Orthop. 2016;50(6):581-3.

4. Alspach JG. A case of plagiarism: lessons for editors, authors, reviewers, readers, and plagiarists. Crit Care Nurse. 2014;34(5):12-6.

5. Debnath J. Plagiarism: a silent epidemic in scientific writingreasons, recognition and remedies. Med $\mathrm{J}$ Armed Forces India. 2016;72(2):164-7.

6. Mehic B. Plagiarism and self-plagiarism. Bosn J Basic Med Sci. 2013;13(3): 139 .

7. Gnanavel S. Self-plagiarism: the latest ethical dilemma in biomedical research. Indian J Psychol Med. 2014;36(4):448-9.

8. Banwari G, Karia S, Avudaiappan S, et al. Modafinil augmentation of atypical antipsychotic agents: duplicate publication, selfplagiarism, salami publication, and other matters. Indian J Psychol Med. 2016;38(1):86-7.

9. Peeran SW, Ahmed AM, Mugrabi MH, et al. Simple steps to avoid plagiarism and improve scientific writing. Libyan J Med. 2013;8:21825.

10. Sapatnekar SM. Plagiarism. J Assoc Physicians India. 2004:52:527-30.

11. Gerding AB. Ethical dilemmas in publishing. A rising tide of plagiarism? J Prosthodont. 2012;21:431-2.

12. Satyanarayana K. Plagiarism: a scourge afllicting the Indian science. Indian J Med Res. 2010;131:373-6. 
13. Nichani AS. Making sense of science: sometimes plagiarized, sometimes not! J Indian Soc Periodontol. 2015;19(4):367.

14. Harriman S, Patel J. Text recycling: acceptable or misconduct? BMC Med. 2014;12:148.

15. Shashikiran ND. Plagiarism and academic integrity. J Indian Soc Pedod Prev Dent. 2014;32:1-2.

16. Roig M. Avoiding plagiarism, self-plagiarism, and other questionable writing practices: a guide to ethical writing (Revised online version published 2015).

17. Keyvanara M, Ojaghi R, Sohrabi MC, et al. Experiences of experts about the instances of plagiarism. J Educ Health Promot. 2013;2:32.

18. Juyal D, Thawani V, Thaledi S. Rise of academic plagiarism in India: reasons, solutions and resolution. Lung India. 2015;32(5):542-3.
19. Natarajan S. Plagiarism-one disease, many manifestations. Indian J Ophthalmol. 2015;63(4):299.

20. Rathore FA, Farooq F. Plagiarism detection softwares: useful tools for medical writers and editors. JPMA J Pak Med Assoc. 2014;64(11):1329.

21. Wiwanitkit V. Simultaneous submission, duplicate publication, self-plagiarism and the proper management. J Minim Access Surg. 2014;10(1):51.

22. Amos KA. The ethics of scholarly publishing: exploring differences in plagiarism and duplicate publication across nations. J Med Libr Assoc. 2014;102(2):87-91. 